\title{
Role of Leukotrienes on Protozoan and Helminth Infections
}

\author{
Alexandre P. Rogerio ${ }^{1}$ and Fernanda F. Anibal ${ }^{2}$ \\ ${ }^{1}$ Laboratory of Experimental Immunopharmacology, Federal University of Triângulo Mineiro, Rua Vigário Carlos, \\ 162. 38025-380 Uberaba, MG, Brazil \\ ${ }^{2}$ Department of Morphology and Pathology, Federal University of São Carlos, Rodovia Washington Luis, km 235 Caixa Postal 676, \\ 13565-905 São Carlos, SP, Brazil
}

Correspondence should be addressed to Alexandre P. Rogerio, alexprogerio@biomedicina.uftm.edu.br

Received 15 November 2011; Accepted 30 January 2012

Academic Editor: Carlos Henrique Serezani

Copyright (C) 2012 A. P. Rogerio and F. F. Anibal. This is an open access article distributed under the Creative Commons Attribution License, which permits unrestricted use, distribution, and reproduction in any medium, provided the original work is properly cited.

\begin{abstract}
Leukotrienes (LTs), formed by the 5-lipoxygenase-(5-LO-) catalyzed oxidation of arachidonic acid, are lipid mediators that have potent proinflammatory activities. Pharmacologic or genetic inhibition of 5-LO biosynthesis in animals is associated with increased mortality and impaired clearance of bacteria, fungi, and parasites. LTs play a role in the control of helminth and protozoan infections by modulating the immune system and/or through direct cytotoxicity to parasites; however, LTs may also be associated with pathogenesis, such as in cerebral malaria and schistosomal granuloma. Interestingly, some proteins from the saliva of insect vectors that transmit protozoans and secreted protein from helminth could bind LTs and may consequently modulate the course of infection or pathogenesis. In addition, the decreased production of LTs in immunocompromised individuals might modulate the pathophysiology of helminth and protozoan infections. Herein, in this paper, we showed the immunomodulatory and pathogenic roles of LTs during the helminth and protozoan infections.
\end{abstract}

\section{Introduction}

Leukotrienes (LTs), first described by Samuelsson's group $[1,2]$, are a class of lipid mediators involved in several diseases but classically known for their effects on asthma and allergy. The generation of leukotrienes (LTs) is dependent upon the action of 5-lipoxygenase (5-LO) in association with membrane-bound 5-lipoxygenase-activating protein (FLAP) on arachidonic acid (AA). AA is derived through the action of cytosolic phospholipase $\mathrm{A}_{2}\left(\mathrm{CPLA}_{2}\right)$ and/or secreted phospholipase $\mathrm{A}_{2}\left(\mathrm{sPLA}_{2}\right)$ on membrane phospholipids [3]. $\mathrm{LTA}_{4}$, an unstable precursor of all leukotrienes, is quickly metabolized to one of the two different classes of LTs, $\mathrm{LTB}_{4}$ (by $\mathrm{LTA}_{4}$ hydrolase) or $\mathrm{LTC}_{4}$ (by $\mathrm{LTC}_{4}$ synthase) and its metabolites $\left(\mathrm{LTD}_{4}\right.$ and $\left.\mathrm{LTE}_{4}\right)$ [4]. Collectively, $\mathrm{LTC}_{4}$, $\mathrm{LTD}_{4}$, and $\mathrm{LTE}_{4}$ were previously known as the slow-reacting substance of anaphylaxis (SR-A) and are currently termed the cysteinyl LTs (cysLTs) $[3,4]$. The receptors for $\mathrm{LTB}_{4}$ (BTL1 and BTL2) and cysteinyl LTs (CysLT1 and CysLT2) are cell surface $\mathrm{G}$ protein-coupled receptors [3]. Additionally, some studies support the existence of other CysLT receptors $[5,6]$. Some cells express both BTLs and cysLTs; however, the expression of these receptors differs in different cells types. In addition, these receptors are also expressed on peripheral blood leukocytes $[7,8]$. LT receptors and 5-LO are expressed mainly in immune cells [6], and LTs play important roles in innate and adaptive immune responses and are involved in several inflammatory and infectious diseases $[4,9]$. For example, cysLTs increase vascular permeability and edema, and $\mathrm{LTB}_{4}$ is involved in leukocyte chemotaxis, lysosomal enzyme secretion, neutrophil degranulation, adhesion molecule expression, defensins and nitric oxide (NO) production, phagocytosis, and other functions [9]. LTs are produced during the interaction of phagocytes and microorganisms in vitro and experimental infections in vivo [9]. Pharmacologic or genetic approaches to reduce or block the LT biosynthesis pathways decrease the phagocytic and antimicrobial activities against bacteria [10], fungi [11], and parasites [12, 13]. In addition, immunodeficient individuals, such as HIV patients, are characterized by low LT production [14], which has been associated with impaired immune responses and infection control. LTs play important roles in both Th1 and Th2 immune responses, which are involved in the defense against protozoan and helminth infections, 
respectively. In light of the current research on the role of LTs in infectious diseases, we have divided the current review into two sections focusing on (1) protozoan infection and (2) helminth infection.

\section{Leukotrienes and Protozoan Infection}

Each year, protozoan parasites infect many people worldwide, mainly in developing countries, causing serious health, political, social, and economic problems. The major protozoan parasites with clinical importance for human diseases are Plasmodium ssp, Leishmania ssp, Trypanosoma cruzi, Toxoplasma gondii, Trichomonas vaginalis, and Entamoeba histolytica [15-17]. The first three of these organisms are obligate intracellular protozoan parasites that are transmitted to vertebrate hosts by insect vectors. T. gondii is also an obligate intracellular protozoan parasite; however, its transmission to human hosts occurs by ingestion of raw or undercooked meat containing tissue cysts or food or water contaminated with oocysts. T. vaginalis and $E$. histolytica are extracellular protozoan parasites. T. vaginalis is transmitted sexually (trophozoites) and E. histolytica is transmitted through food and water contaminated with cysts [15-17]. Protective immunity against protozoans is mediated mainly by T helper 1 (Th1) responses which are characterized by the production of inflammatory cytokines, such as IL-12, which is required for the development of the Th1 immune response, and interferon gamma (IFN- $\gamma$ ) and tumor necrosis factor alpha $(\mathrm{TNF}-\alpha)$, which activate macrophages to produce NO, which is involved in the control of parasite replication $[16,18-20]$.

Reiner and Malemud [21, 22] conducted the first studies to demonstrate the role of leukotrienes in protozoan infection (Leishmania spp). Research in this area has increased in recent decades. The main effects of LTs, in both innate and adaptative immune responses, during the protozoan infections are illustrated in Figure 1. Mouse strains resistant $(\mathrm{C} 57 \mathrm{BL} / 6)$ to Leishmania infection mount Th1 immune responses against Leishmania. In contrast, infection of susceptible mouse strain $(\mathrm{BALB} / \mathrm{c})$ is associated with the development of a Th2 immune response. In vitro studies have demonstrated increased $\mathrm{LTC}_{4}$ production in splenocytes and macrophages from L. donovani-infected or uninfected BALB/c mice upon stimulation with nonspecific (phytohemagglutinin) or specific (L. donovani amastigotes) stimuli $[21,22]$. In another study, splenocytes from BALB/c mice stimulated with antigens from $L$. major promastigotes displayed increased $\mathrm{LTB}_{4}$ and IL-4 production with concomitant decreases in IFN- $\gamma$ and TNF- $\alpha$ production [23]. Serezani et al. [24] demonstrated an increase in the parasite burden of BALB/c macrophages infected with L. amazonensis when compared to macrophages from the resistant mouse strain $\mathrm{C} 3 \mathrm{H} / \mathrm{HePas}$. This effect was associated with lower levels of $\mathrm{LTB}_{4}$ in macrophages from BALB/c mice. In agreement with this finding, macrophages from either susceptible or resistant mice treated with MK0591 (FLAP inhibitor) and U75302 (BLT1 antagonist), but with not MK571 (cysLT1 antagonist), as well as macrophages derived from 5-LO-deficient mice, exhibited decreased leishmanicidal activity. Interestingly, treatment with exogenous $\mathrm{LTB}_{4}$ or $\mathrm{LTD}_{4}$ favored parasite killing by macrophages from BALB/c mice. Supporting these in vitro results, susceptible and resistant mice treated with zileuton (inhibitor of 5-LO) or 5-LO-deficient mice infected with L. amazonensis displayed larger footpad lesions than nontreated or wild type animals [24].

The success of Lutzomyia longipalpis, an insect vector of the Leishmania ssp, at blood feeding on mammals depends on the inhibition of the immediate inflammatory response (e.g., increased vascular permeability, swelling, pain, and itching). It is well known that active substances in the saliva of hematophagous arthropods facilitate the uptake of blood by counteracting host hemostatic, inflammatory and immunological defenses [25-28]. Mixed lysates from the salivary glands of $L$. longipalpis significantly increased the cutaneous lesions and/or parasite loads in the footpads of mice infected with L. major or L. braziliensis when compared to infected animals not exposed to the saliva lysates $[29,30]$. In addition, the modulation of infection by saliva was IL-4dependent [29]. In agreement with these results, the salivary gland extract of $L$. longipalpis exhibited anti-inflammatory activities by decreasing TNF- $\alpha$ and $\mathrm{LTB}_{4}$ production, neutrophil numbers, and $\mathrm{LTB}_{4}$-induced chemotactic activity in a murine ovalbumin-induced peritonitis model [31]. In addition, IL-10 and IL-4 production was increased in this model. Taken together, these findings suggest that LTs, and particularly $\mathrm{LTB}_{4}$, play a role in immune response to Leishmania infection by promoting leishmanicidal activity and consequently, control of infection. Therefore, the modulation of $\mathrm{LTB}_{4}$ during infection in association with the modulation of the immune system during Leishmania transmission (by saliva from the insect vector) in synergism with genetic factors (susceptibility; Th2) could markedly affect Leishmania infection in humans.

The components derived from the saliva of the arthropod vector of malaria (e.g., Anopheles stephensi) have also pharmacologic effects, such as inhibition of inflammation and coagulation [32], similar to those observed in the saliva of insect vectors of Leishmania. In addition, these proteins also have the ability to neutralize inflammatory small molecules by rapid binding. The AnSt-D7L1 protein produced by $A$. stephensi binds cysLTs $\left(\mathrm{LTC}_{4}, \mathrm{LTD}_{4}\right.$, and $\left.\mathrm{LTE}_{4}\right)$ but does not chemically modify them. AnSt-D7L1 effectively inhibited $\mathrm{LTC}_{4}$-induced ileal contraction by binding $\mathrm{LTC}_{4}$, thereby preventing interactions between this molecule and its appropriate cellular receptor [25]. The effects of $\mathrm{LTC}_{4}$ inhibition on the course of malaria infection as well as the influence in the malaria pathogenesis are not known.

In the experimental cerebral malaria model, mice infected with Plasmodium berghei showed increased $\mathrm{LTB}_{4}$ production in the serum. Interestingly, treatment with aspirin, which may direct arachidonic acid metabolism away from the cyclooxygenase (COX) pathway and toward the LO pathway [33], induced increased parasitemia and death of infected mice. This effect was associated with the overproduction of $\mathrm{LTB}_{4}$ in the serum [34]. In agreement with these results, children with cerebral malaria treated with salicylate demonstrated complications of severe malaria (metabolic 


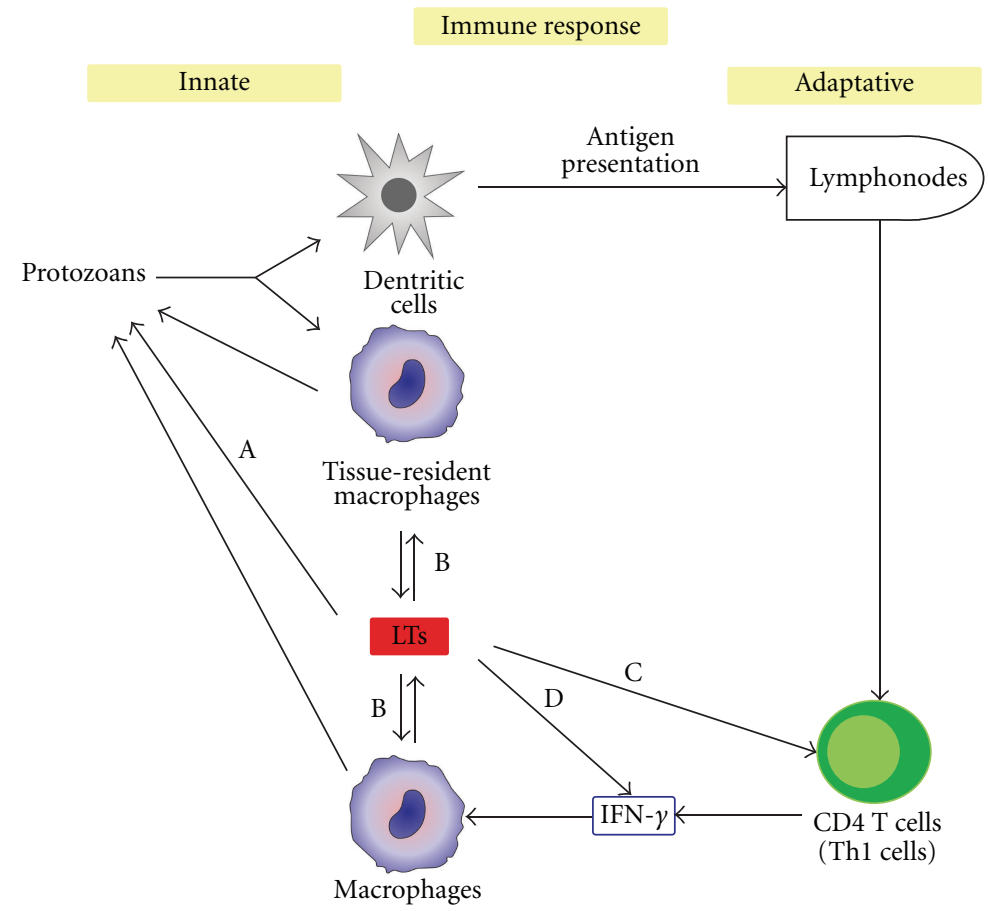

Figure 1: Modulation of innate and adaptive immune responses by LTs during the protozoan infections. Protective immunity against protozoans is mainly mediated by Th1 responses characterized by the production of inflammatory cytokines, such as IFN- $\gamma$, which activate macrophages to control of parasite replication. Macrophages are a source of LTs. (A) $\mathrm{LTB}_{4}$ induces cytotoxicity in parasites. (B) LTB 4 and $\mathrm{LTD}_{4}$ favored parasite killing by macrophages. (C) $\mathrm{LTB}_{4}$ induces chemotaxis of $\mathrm{CD}^{+} \mathrm{T}$ cells. (D) LTB 4 induces the production of Th1 cytokines, such as IFN- $\gamma$.

acidosis, hypoglycemia, and death) [35]. Although IFN- $\gamma$ plays a protective role in malaria infection, it has also been associated with the immunopathology of cerebral malaria $[36,37]$. Besides playing a role in initiating the Th1 immune response mediated by dendritic cells [38], $\mathrm{LTB}_{4}$ is also an inducer of Th1 cytokines, such as IFN- $\gamma$ [39]. Therefore, the overproduction of $\mathrm{LTB}_{4}$ after aspirin treatment in experimental and human cerebral malaria could be associated with the overproduction of IFN- $\gamma$. Further studies are needed to evaluate this hypothesis.

Eryptosis, or suicidal death of erythrocytes, which occurs in a wide variety of diseases including malaria [40], is characterized by cell shrinkage, membrane blebbing, and exposure of phosphatidylserine (PS) at the cell surface [41]. Like apoptotic cells, PS-exposing erythrocytes are identified by macrophages and are engulfed, degraded, and removed from the circulation [42]. Ayi et al. [43] demonstrated increased phagocytosis of mutant red blood cells infected with trophozoites of $P$. falciparum, which may represent a protective mechanism against infection. Remarkably, an in vitro assay demonstrated that erythrocytes were able to produce cysLTs upon energy depletion [44]. In addition, exogenous treatment with $\mathrm{LTC}_{4}$, but not $\mathrm{LTB}_{4}$, stimulated eryptosis. These effects were inhibited by cysLT1 receptor antagonists and by the 5-LO inhibitor (BW B70C) [44]. These results suggest that $\mathrm{LTC}_{4}$ might confer protection during the course of malaria by accelerating the clearance of infected erythrocytes. On the other hand, excessive eryptosis might favor the development of anemia; thus, $\mathrm{LTC}_{4}$ might have a dual effect in malaria pathogenesis.
During T. gondii infection, an efficient immune response is important to contain dissemination of the parasite and to prevent mortality of the host. $\mathrm{LTC}_{4}, \mathrm{LTD}_{4}$, and free AA were detected when murine macrophages from Swiss mice were cultured with viable T. gondii [45]. In contrast, when macrophages from resistant mice (BALB/c; major histocompatibility complex haplotypes $\mathrm{H}^{\mathrm{d}}$ ) [46] or human macrophages [47] were cultured with viable T. gondii, no 5LO products were observed. Accordingly, prior incubation of human macrophages with viable $T$. gondii decreased the $\mathrm{LTB}_{4}$ release induced by the calcium ionophore A23187, suggesting that $T$. gondii inhibits $\mathrm{LTB}_{4}$ production. This effect was restored by IFN- $\gamma$ treatment [47]. In addition, treatment with zileuton (an inhibitor of 5-LO) decreased the toxoplasmacidal activity of IFN- $\gamma$ in human macrophages, whereas exogenous $\mathrm{LTB}_{4}$ promoted intracellular killing of ingested T. gondii in human monocytes [47]. This effect might be associated with the effect of $\mathrm{LTB}_{4}$ on the induction of cytotoxicity (surface membrane vesiculation, extravasation of cytoplasmic contents into a space between the intermembrane spaces and cytoplasmic vacuolization) in T. gondii tachyzoites $[47,48]$. In agreement with these results, 5-LO-deficient mice infected with T. gondii displayed decreased survival as a consequence of an excessive inflammatory response characterized by elevated IL-12 and IFN- $\gamma$ concentrations in the serum and $\mathrm{CD}^{+}$and $\mathrm{CD} 8^{+} \mathrm{T}$-cell infiltration in the brain tissue and not of increased parasitic burden [49]. The increased inflammation in the absent of LTs might indicate a compensatory mechanism to control the parasite infection. Taken together, these findings suggest 
that the downregulation of LTs production, and particularly of $\mathrm{LTB}_{4}$, by $T$. gondii might be considered an evasion mechanism, as this lipid mediator can promote cytotoxicity and toxoplasmacidal activity. Thus, $\mathrm{LTB}_{4}$ plays an important role in toxoplasmosis.

Studies by our group and others have demonstrated reduced LT synthesis (e.g., $\mathrm{LTB}_{4}$ ) in HIV-infected subjects [14, 50]. Although the clinical manifestation of T. gondii infection is usually asymptomatic in immunocompetent individuals, immunocompromised individuals, such as HIV-seropositive patients, exhibit reactivation of latent tissue cysts (bradyzoites become tachyzoites) and consequent toxoplasmic encephalitis or retinochoroiditis [51, 52]. Interestingly, in agreement with these results, the $\mathrm{LTB}_{4}$ and $\mathrm{LTC}_{4}$ concentrations in the cerebrospinal fluid of HIV-1-seropositive patients with toxoplasmic encephalitis but not those of HIV1 -seropositive patients without inflammatory disease or encephalitis were below the detection limit [53]. These results support those described above and suggest that the reduced basal production of LTs in HIV-1-seropositive patients synergizes with the suppression of LTs by T. gondii. Moreover, this synergistic decrease in LT production might contribute to the pathogenesis of cerebral toxoplasmosis through the increased reactivation of bradyzoites from tissue cysts and the reduced control of the parasitic infection.

Protective immunity against toxoplasmosis and Chagas disease is mediated by Th1 cells, $\mathrm{CD}^{+} \mathrm{T}$ cells, and IFN- $\gamma$ [16]. Chagas' heart disease is a severe clinical manifestation of Trypanosoma cruzi infection [54]. In chronic Chagas disease, cardiomyopathy is observed as an inflammatory process characterized by the infiltration of $\mathrm{T}$ cells and macrophages, resulting in myocarditis, fibrosis, and heart fiber damage [54]. Treatment with LT inhibitors has demonstrated beneficial effects in cardiovascular pathologies $[55,56]$. $\mathrm{T}$ lymphocytes from patients with chronic Chagas' heart disease [57] or from chagasic mice [58] show increased contractile activity (positive inotropic and chronotropic effects) of heart (atrial) in an in vitro assay. Interestingly, pretreatment with lipoxygenase inhibitors (NDGA) or a cysLT receptor antagonist (FPL 55712) decreased this effect. In a separate study, $\mathrm{LTC}_{4}$ production was observed in the supernatants of murine atria cocultured with $\mathrm{T}$ lymphocytes from chagasic mice [58]. In accordance with these results, $\mathrm{LTB}_{4}$ induces chemotaxis of lymphocytes $\left(\mathrm{CD} 4^{+} / \mathrm{CD} 8^{+} \mathrm{T}\right.$ cells) $[8,59]$. Therefore, LTs might modulate the cardiac pathology of Chagas disease by modulating the immune response profile during this infection.

$\mathrm{LTB}_{4}[60]$ and $\mathrm{LTC}_{4}[61]$ also increased the phagocytic and trypanocidal activity of murine macrophages incubated with $T$. cruzi trypomastigotes in vitro. In addition, $\mathrm{LTB}_{4}$ restored NO and TNF- $\alpha$ levels, which were decreased by an $\mathrm{LTB}_{4}$ receptor antagonist (CP-105,696) [62]. CP-105,696 treatment also decreased the trypanocidal activity of IFN- $\gamma$ in murine macrophages. With the use of pharmacologic $\left(\mathrm{LTB}_{4}\right.$ receptor antagonist and LO inhibitors) and genetic approaches (5-LO-deficient mice), researchers have demonstrated increased parasitemia in mice infected with T. cruzi [63-65]. In addition, the following anti-inflammatory profiles were observed in T. cruzi infection: (1) decreased leuko- cyte infiltration in the heart; (2) reduced numbers of $\mathrm{CD} 4^{+}$, $\mathrm{CD}^{+}$, and IFN- $\gamma$-producing cells in the heart; (3) decreased fibrosis in cardiac tissues; (4) decreased iNOS expression and NO production in the heart; (5) decreased TNF- $\alpha$ and IFN- $\gamma$ in the heart; (6) increased IL-10 in the heart; and (7) decreased oxidative stress in erythrocytes [63-65]. The survival of 5-LO-deficient mice was greatest when the animals were infected with low number of parasites [64] when compared to animals infected with higher number of parasites [65]. Taken together, these findings suggest that LTs, and specifically $\mathrm{LTB}_{4}$, play important roles in the control of Chagas disease.

Trichomoniasis is the most common sexually transmitted disease. The supernatant of viable $T$. vaginalis induced increased $\mathrm{LTB}_{4}$ production in neutrophils in an IgGand complement-(C5-) dependent manner. This effect was decreased by SC-41930 (LTB 4 antagonist) treatment [66]. In the vaginal discharges from patients with vaginal trichomoniasis, Shaio and Lin [67] demonstrated a positive correlation between neutrophils and $\mathrm{LTB}_{4}$ production in symptomatic patients when compared to asymptomatic patients. These results suggest that $\mathrm{LTB}_{4}$ is involved in the inflammation and symptoms of trichomoniasis. The most relevant effects of $\mathrm{LTB}_{4}$ in protozoan infections are illustrated in Figure 2.

Entamoebiasis causes high morbidity and mortality in the developing world. Peritoneal and splenic macrophages from naïve mice incubated directly with E. histolytica trophozoites or with their excretory/secretory products show increased $\mathrm{LTC}_{4}$ production. On the other hand, peritoneal and splenic macrophages from E. histolytica-infected mice produced low levels of $\mathrm{LTC}_{4}$. Interestingly, amoebic liver abscess-derived macrophages were unable to produce $\mathrm{LTC}_{4}$ [68]. The downregulation of $\mathrm{LTC}_{4}$ by E. histolytica in inflammatory but not naïve macrophages might be associated with the pathogen's evasion mechanisms.

\section{Leukotrienes and Helminthic Infections}

Over one-third of the human population is infected with one or more species of helminths $[69,70]$. Although host immune responses attempt to control or expel the parasites, these organisms can develop evasion strategies to modulate the innate and adaptive immune responses, allowing them to survive. The most prevalent human helminthiases are caused by nematodes (e.g., Ascaris lumbricoides, Strongyloides spp., Enterobius vermicularis, and Trichuris trichiura), including filarial worms (e.g., Brugia malayi and Wuchereria bancrofti), hookworms (e.g., Ancylostoma duodenale and Necator americanus), and trematodes (Schistosoma spp).

Asthma and helminthiasis present similar features and are both controlled by a $\mathrm{CD} 4^{+} \mathrm{T}$-cell immune response. Initial exposure of the immune system to allergic or parasitic antigens leads to the activation of a subset of $\mathrm{T}$ cells known as Th2 cells, which orchestrate the immune response to these exogenous antigens by secreting cytokines, including IL-4, IL-5, and IL-13 [71-74]. In addition, the accumulation of eosinophils in the blood (eosinophilia), as well as in different 


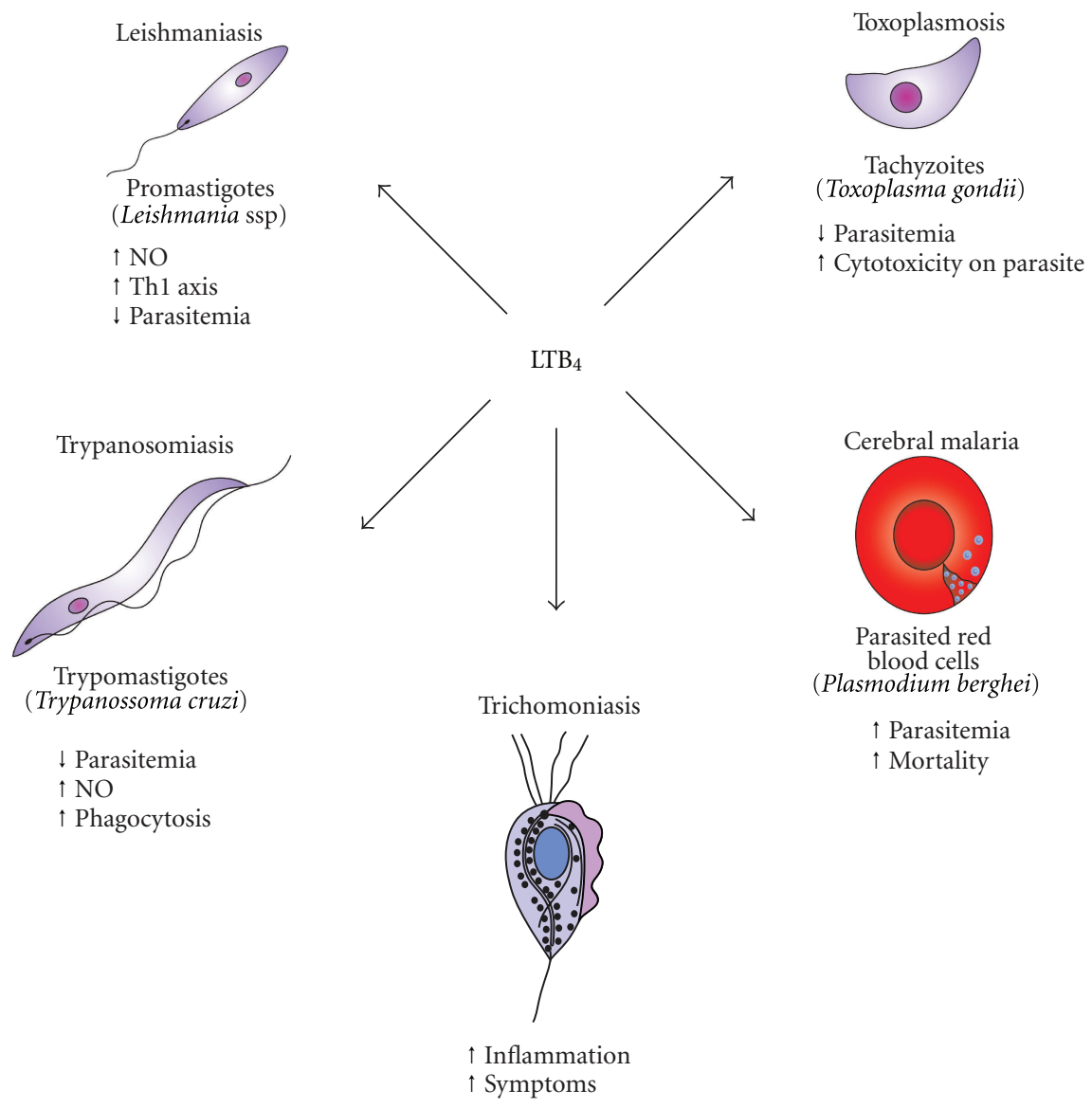

FIGURE 2: Roles of $\mathrm{LTB}_{4}$ on protozoan infections. $\mathrm{LTB}_{4}$ is involved in the control of leishmaniasis, toxoplasmosis, and trypanosomiasis. $\mathrm{LTB}_{4}$ is also involved in the inflammation and symptoms of trichomoniasis. The overproduction of $\mathrm{LTB}_{4}$, after aspirin treatment, could be associated with the exacerbated pathogenesis of cerebral malaria.

organs and tissues [75], is a hallmark of both diseases. Eosinophils are multifunctional cells that are involved in tissue damage as a consequence of the release of cationic proteins [76-79]. In addition, eosinophils are important sources of various inflammatory and regulatory cytokines, chemokines, and lipid mediators, such as LTs [78, 80, 81].

During a helminth infection such as a nematode infection, most of the IgE produced binds to mast cells and basophils through their high-affinity IgE Fc receptor (FceRI) $[82,83]$. Subsequent exposure of immune cells to parasitic antigen induces the degranulation of IgE-sensitized mast cells and the release of both preformed and newly generated mediators [82]. These mediators, such as LTs, function alone or in conjunction with Th2 cytokines to increase the contractility of smooth muscle cells, the permeability of epithelial cells and the production of mucus, thereby contributing to worm expulsion [84]. The experimental gastrointestinal infection of rats with the nematode Trichinella spiralis demonstrated that preimmune rats (previously infected with $T$. spiralis) expelled the nematode $T$. spiralis more rapidly than nonimmune rats. This effect was associated with the increased production of $\mathrm{LTB}_{4}$ and $\mathrm{LTC}_{4}$ in the gut homogenate as well as the release of rat mast cell protease II (RMCPII) in the serum $[85,86]$. LTC 4 causes smooth muscle contrac- tion, increases vascular permeability, and stimulates mucus hypersecretion, and $\mathrm{LTB}_{4}$ recruits and activates inflammatory cells such as eosinophils to favor the expulsion of helminths. Therefore, leukotrienes released from mast cells may effectively participate in protective immune responses resulting in the rapid expulsion of $T$. spiralis and possibly other helminths. The main effects of LTs, in both innate and adaptative immune responses, during the helminth infections are illustrated in Figure 3.

Parasitic worm survival in the host for longer periods depends on the ability of the parasite to evade the host immune system. The ABA-1 protein from Ascaris lumbricoides (human parasite) and Ascaris suum (pig parasite) is released by larvae and adult organisms [87, 88]. This protein binds a range of fatty acids, including LTs [89]. The interaction between ABA-1 and leukotrienes might be associated with an evasion mechanism; however, further studies are needed to evaluate the ability of this interaction to inhibit the biologic effects of LTs in vitro or in vivo.

Brugia malayi is a nematode (roundworm) that can cause lymphatic filariasis in humans. The infective larvae (L3) of Brugia malayi are transmitted to a vertebrate host by an insect vector and undergo two molts to develop into adult worms and complete the life cycle [90]. Interestingly, 


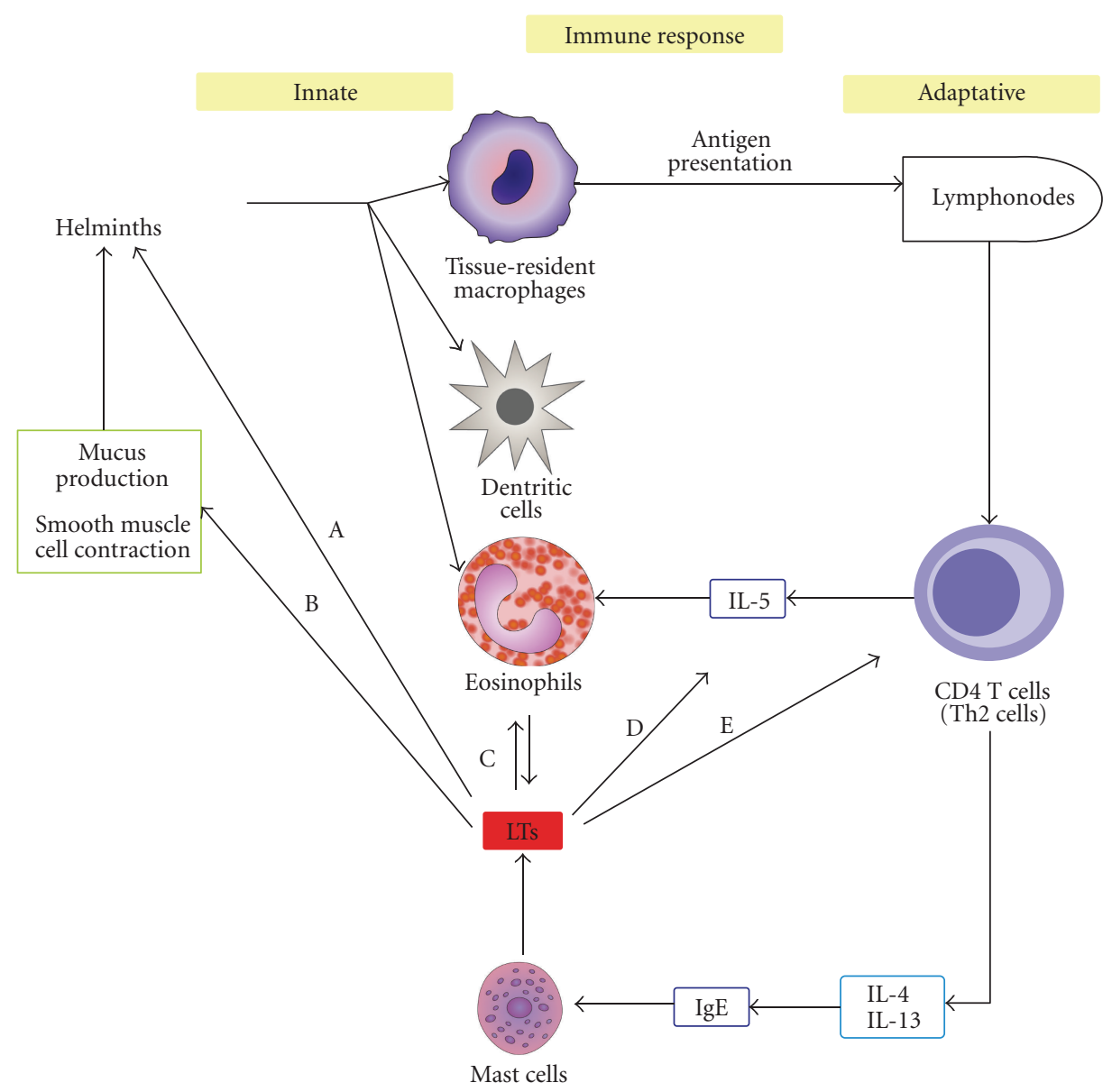

FIGURE 3: Modulation of innate and adaptive immune responses during the helminth infections. Initial exposure of the immune system to parasitic antigens leads to the activation of a subset of T cells known as Th2 cells, which orchestrate the immune response to these exogenous antigens by secreting cytokines, including IL-4, IL-5 and IL-13. The accumulation of eosinophils in the blood and in different organs and tissues as well as the degranulation of IgE-sensitized mast cells is hallmarks of helminthiasis. Eosinophils and mast cells are sources of LTs. (A) CysLTs are required for molting of the infectious larvae (e.g., Brugia malayi larvae). (B) CysLTs, alone or in conjunction with Th2 cytokines, cause contractility of smooth muscle cells, the permeability of epithelial cells, and the production of mucus, thereby contributing to worm expulsion. (C) $\mathrm{LTB}_{4}$ recruits and activates inflammatory cells such as eosinophils to favor the kill of helminths. (D) LTB 4 regulates IL-5 production by human $\mathrm{T}$ lymphocytes and consequently contributes to parasite elimination. (E) $\mathrm{LTB}_{4}$ induces chemotaxis of CD4 ${ }^{+} \mathrm{T}$ cells.

treatment with inhibitors of lipoxygenases (AA861) or cysLT biosynthesis (ethacrynic acid or acivicin) or with a cysLT antagonist (zafirlukast) inhibited the Brugia malayi L3 larvae from molting to the L4 stage without altering their survival or motility. In contrast, U-75302, an antagonist of the $\mathrm{LTB}_{4}$ receptor $\mathrm{BTL}_{1}$, failed to inhibit molting [91]. The $\gamma$-glutamyl transpeptidase, the enzyme that converts $\mathrm{LTC}_{4}$ to $\mathrm{LTD}_{4}$, has been cloned from Brugia malayi (adult worms) [92]. In another filaria that causes human infection, Dirofilaria immitis, the glutathione S-transferase, which can function as an LTC $_{4}$ synthase, was found in the cytosol of adult worms [93]. These results demonstrated that a lipoxygenase pathway involved in the generation of cysLTs could be required for molting of the infectious larvae and may possibly have some role in the adult worm. In vivo models of infection with $B$. malayi could be used to better understand the role of cysLTs in the pathogenesis of filariasis.

It is widely known that some types of infections in immunocompromised individuals are critical in determining the severity of the disease. The immunosuppression observed in HIV-seropositive subjects has been associated with Strongyloides spp infections of abnormally high intensity [94]. Interestingly, reduced LT production was observed in HIVseropositive patients [14]. In an experimental model that mimics human strongyloidiasis (mice infected with Strongyloides venezuelensis), an increase in the concentration of $\mathrm{LTB}_{4}$ but not of $\mathrm{LTC}_{4}$ was observed in the lung and small intestines. In addition, increased larvae recovery in the lung and/or increased worm burdens in the intestines were observed in animals treated with MK886 (a selective inhibitor of 5-lipoxygenase-activating protein (FLAP)) and in 5-LOdeficient mice than in control animals. Moreover, treatment of animals with MK886 resulted in decreases of $\mathrm{IgG}_{1}$ and $\mathrm{IgE}$ levels in serum, eosinophil numbers in the blood, peritoneal cavity and bronchoalveolar fluid volumes and IL-5 concentrations in the lung homogenate as well as increased levels of IL-12, which is involved in the Th1 response. IL-5 is the major cytokine involved in the accumulation of eosinophils 
in the blood during allergic inflammation and parasitic infections. This cytokine is essential for eosinophil migration from the bone marrow to the blood $[72,95]$ and specifically supports the terminal differentiation and proliferation of eosinophil precursors as well as the activation of mature eosinophils [96-99]. $\mathrm{LTB}_{4}$ regulates IL-5 production by human T lymphocytes [100] and consequently contributes to parasite elimination. These findings suggest that LTs, and specifically $\mathrm{LTB}_{4}$, might be necessary to control S. stercoralis infection. Thus, the reduced levels of $\mathrm{LTB}_{4}$ observed in HIVseropositive subjects might favor opportunistic hyperinfection with S. stercoralis; however, further human studies are needed to evaluate this association.

Toxocara canis is an intestinal parasite of dogs and is the etiologic agent of toxocariasis, also known as visceral larva migrans syndrome (VLMS). Infection of both humans and animals with T. canis is characterized by eosinophilia in the blood and tissues, increased total serum IgE, and inflammation of the upper respiratory system $[72,95,101-$ 104]. During the inflammatory response, leukocyte recruitment is directly related to the expression of adhesion molecules, which allows the transmigration of these blood cells to the tissues. The integrin adhesion molecules directly contribute to this process [105]. It has been proposed that the $\beta_{2}$ integrin Mac-1 (CD11b/CD18) and the $\beta_{1}$ integrin VLA-4 (CD49d/CD29) adhesion molecules are the major molecules involved in cytokine- and chemokine-induced adhesion and migration of eosinophils in vitro [106, 107]. LTs can enhance the expression of Mac-1 on eosinophil cell surfaces [108]. In mice, T. canis infection causes early upregulation of Mac-1 with late changes in VLA-4 profiles on both peritoneal cavity fluid and bronchoalveolar lavage fluids, whereas MK886 treatment promoted the opposite effect. In addition, LT inhibition had a clear impact on eosinophil recruitment to tissues and on blood eosinophilia throughout the course of infection [12]. In another study, in addition to increased eosinophil numbers, the researchers showed increased numbers of mast cells in the peritoneum, lungs, and small intestines of $T$. canis-infected rats. Interestingly, these animals increased the concentration of $\mathrm{LTB}_{4}$ in the serum and this was correlated with mast cell and eosinophil accumulation and/or recruitment [109]. Thus, LTs might play an important role in eosinophilic inflammation during toxocariasis by inducing leukocytes recruitment and modulating the expression of adhesion molecules.

In schistosomiasis, a granulomatous lesion is observed during chronic infection and causes a range of morbidities [110]. LTs can control parasite infection by modulating immune responses and through direct cytotoxic effects on the parasite. $\mathrm{LTB}_{4}$, but not cysLTs (LTC 4 and $\mathrm{LTD}_{4}$ ), enhanced the ability of neutrophils and eosinophils to kill the schistosomula of $S$. mansoni in a complement-dependent manner [111]. The cytotoxicity of eosinophils against helminths has been associated with the expression of cellular receptors (high affinity IgE receptor, FceRI) and adhesion molecules and with degranulation and the release of cationic proteins [112]. In an in vitro assay, IgE-coated schistosomula induced eosinophil adherence, resulting in the death of the parasites. In addition, the release of $\mathrm{LTC}_{4}$ was observed during this interaction [113]. In agreement with this finding, schistosomula can produce $\mathrm{LTB}_{4}$ and $\mathrm{LTC}_{4}$ [114]. The function of LTs in schistosomula is not known; however, their production might accelerate parasite elimination and/or modulate the pathogenesis of schistosomiasis.

Schistosome cercariae enter mammalian hosts via a percutaneous route [115]. In addition to the proteolytic enzymes produced by cercariae, host-derived skin essential fatty acids and LTs including $\mathrm{LTB}_{4}$ also play important roles in the penetration of the skin by the parasite. In an in vitro assay, increased penetration rates were correlated with increased LTs levels. In addition, penetration was reduced upon treatment with a 5-LO inhibitor $[116,117]$.

Hepatic granulomatous inflammation is observed during schistosomal infection of both humans and mice [110]. Th2 cell-associated cytokines modulate the development of schistosome egg-induced granulomas. Hepatic stellate cells (HSCs) are involved in liver remodeling due to collagen production and deposition of extracellular matrix as a consequence of proliferative and fibrogenic phenotypes induced by several mediators (cytokines, lipid peroxide, and others) [118]. mRNA for 5-LO, FLAP and $\mathrm{LTC}_{4}$-synthase and 5-LO expression was observed in HSCs from schistosomal granulomas of S. mansoni-infected mice [119]. Consequently, these cells produced cysLTs, but not $\mathrm{LTB}_{4}$, and the production of cysLTs was increased upon treatment with transforming growth factor beta (TGF- $\beta$, a fibrogenic cytokine). The proliferation induced by TGF- $\beta$ in HSCs from schistosomal granulomas of $S$. mansoni-infected 5-LO-deficient mice or wild type mice treated with zileuton (5-LO inhibitor) was reduced [119]. In addition, $\mathrm{LTC}_{4}$ induced TGF- $\beta$ production [120], suggesting a synergic effect in schistosomal granulomas. In another study, dipeptidases were isolated from extracts of hepatic granulomas of mice infected with S. mansoni; these enzymes increased the hydrolysis of $\mathrm{LTD}_{4}$ to $\mathrm{LTE}_{4}$ [121], potentially accelerating the metabolism of LTs and decreasing their effects on liver remodeling. Moreover, $\mathrm{LTB}_{4}$ and $\mathrm{LTC}_{4}$ are produced by schistosomula and adult females, while males produced only $\mathrm{LTB}_{4}$ [113]. Together, these results suggest that cysLT inhibition might influence liver remodeling in S. mansoni infection. In this way, $\mathrm{CysLT}_{1}$ antagonists (such as montelukast, zafirlukast, and pranlukast) $[4,122,123]$, which are currently used in asthma treatment, could be evaluated for their effects on schistosomal granuloma remodeling in experimental or human schistosomiasis. The main roles of LTs during the helminth infection are illustrated in Figure 4.

Similar to schistosomiasis, fasciolosis causes liver alterations, which can range from fibrosis to cirrhosis. Fasciolosis is considered both a human health concern and a veterinary problem (zoonoses) [124]. During the course of F. hepatica infection in sheep, a reduction in serum $\mathrm{LTB}_{4}$ was observed when compared to control animals. Interestingly, $\mathrm{LTB}_{4}$ was produced in both the culture supernatant and the homogenate of $F$. hepatica adult parasites recovered from the bile duct 20 weeks after infection [125]. Moreover, recruitment of leukocytes consisting mainly of eosinophils, macrophages, and lymphocytes was observed in the livers 


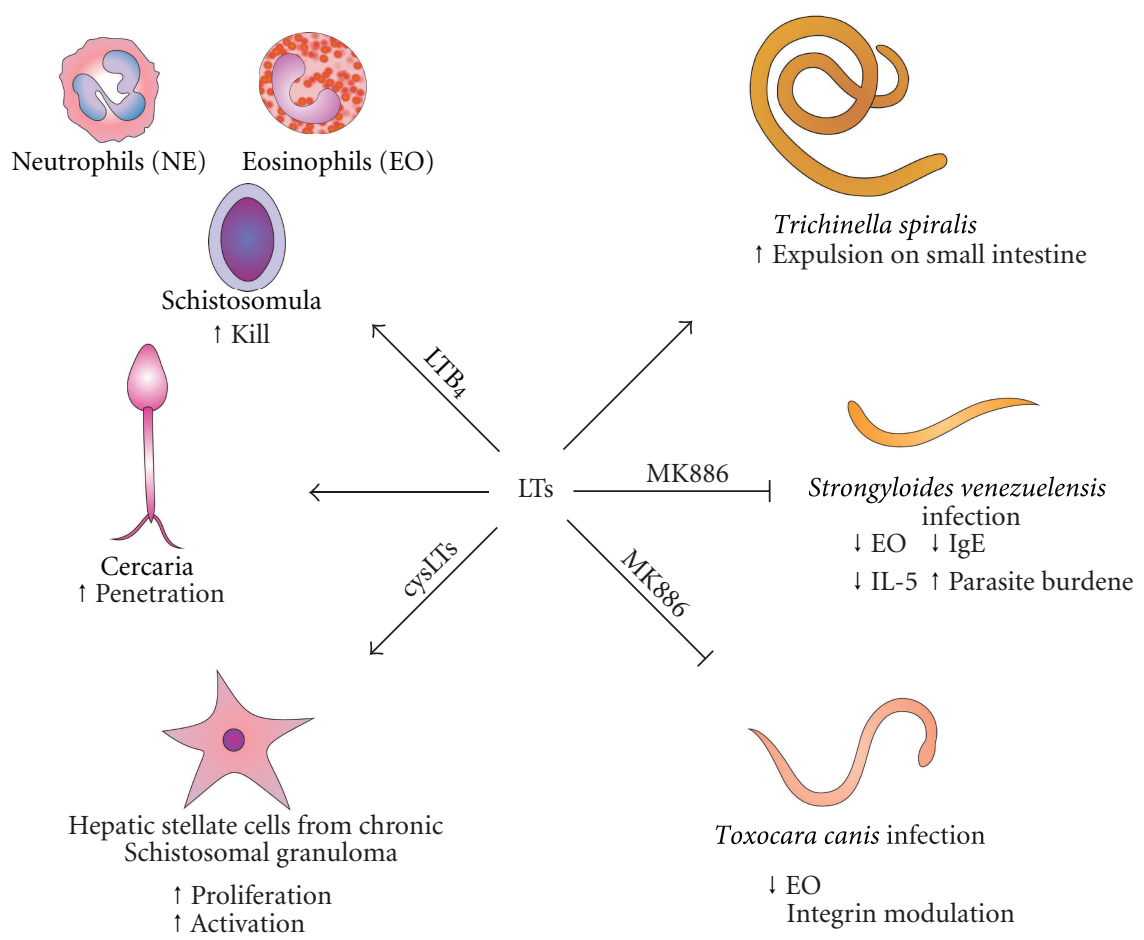

FIGURE 4: An overview of main effects of LTs in helminth infections. LTs participate of expulsion of T. spiralis in the intestine. The inhibition of LTs resulted in increases of parasitemia and decreases IgE levels, eosinophil numbers and IL-5 concentrations in mice infected with $S$. venezuelensis. LT inhibition also reduced the eosinophil recruitment to tissues and on blood eosinophilia in experimental T. canis infection. $\mathrm{LTB}_{4}$ enhanced the ability of neutrophils and eosinophils to kill the schistosomula of $S$. mansoni. LTs play important roles in the penetration of the skin by the schistosome cercariae. CysLTs are involved in the proliferation and activation of hepatic stellate cells from $S$. mansoni granulomas.

of goats infected with $F$. hepatica [126]. In this way, $\mathrm{LTB}_{4}$ produced by host inflammation in synergy with that produced by the parasite could contribute to liver alterations and consequent pathology.

\section{Conclusion}

LTs are associated with the control of helminth and protozoan infections through their ability to modulate inflammatory processes and/or to promote direct cytotoxicity of protozoans. In addition, LTs may also be associated with exacerbated pathogenesis in protozoan diseases, such as cerebral malaria, and helminthic diseases, such as schistosomal granulomas. Interestingly, some helminths (B. malayi) might use the LTs to complete their development to adult worms. In addition, other parasites produce LTs ( $S$. mansoni and $F$. hepatica) or produce enzymes involved in LT biosynthesis (Dirofilaria immitis). Taken together, these findings demonstrate that LTs play significant roles in protozoan and helminth infections.

\section{List of Abbreviations}

5-LO: 5-Lipoxygenase

AA: Arachidonic acid

cysLTs: Cysteinyl leukotrienes
FLAP: Membrane-bound 5-lipoxygenase-activating protein

HSCs: Hepatic stellate cells

IFN- $\gamma$ : Interferon-gamma

Ig: Immunoglobulin

IL: Interleukin

LTs: Leukotrienes

NO: $\quad$ Nitric oxide

PS: $\quad$ Phosphatidylserine

TGF- $\beta$ : Transforming growth factor-beta

Th: $\quad$ Thelper

TNF- $\alpha$ : Tumor necrosis factor-alpha

VLMS: Visceral larva migrans syndrome.

\section{Acknowledgments}

The authors would like to thank Dr. Anderson Sá-Nunes from the Laboratory of Experimental Immunology, Institute of Biomedical Sciences, University of Sao Paulo, Brazil, for critical reading of this paper and Ana Cristina Hallal Prata for helping to draw the figures.

\section{References}

[1] P. Borgeat, M. Hamberg, and B. Samuelsson, "Transformation of arachidonic acid and homo $\gamma$ linolenic acid by 
rabbit polymorphonuclear leukocytes. Monohydroxy acids from novel lipoxygenases," Journal of Biological Chemistry, vol. 251, no. 24, pp. 7816-7820, 1976.

[2] P. Borgeat and B. Samuelsson, "Transformation of arachidonic acid by rabbit polymorphonuclear leukocytes. Formation of a novel dihydroxyeicosatetraenoic acid," Journal of Biological Chemistry, vol. 254, no. 8, pp. 2643-2646, 1979.

[3] P. Montuschi and M. L. Peters-Golden, "Leukotriene modifiers for asthma treatment," Clinical and Experimental Allergy, vol. 40, no. 12, pp. 1732-1741, 2010.

[4] M. Peters-Golden and W. R. Henderson Jr, "Mechanisms of disease: leukotrienes," New England Journal of Medicine, vol. 357, no. 18, pp. 1798-1854, 2007.

[5] A. Maekawa, Y. Kanaoka, W. Xing, and K. F. Austen, "Functional recognition of a distinct receptor preferential for leukotriene E4 in mice lacking the cysteinyl leukotriene 1 and 2 receptors," Proceedings of the National Academy of Sciences of the United States of America, vol. 105, no. 43, pp. 16695 16700, 2008.

[6] O. Rådmark and B. Samuelsson, "Regulation of the activity of 5-lipoxygenase, a key enzyme in leukotriene biosynthesis," Biochemical and Biophysical Research Communications, vol. 396, no. 1, pp. 105-110, 2010.

[7] G. E. Rovati and V. Capra, "Cysteinyl-leukotriene receptors and cellular signals," TheScientificWorldJournal, vol. 7, pp. 1375-1392, 2007.

[8] A. M. Tager and A. D. Luster, "BLT1 and BLT2: the leukotriene B4 receptors," Prostaglandins Leukotrienes and Essential Fatty Acids, vol. 69, no. 2-3, pp. 123-134, 2003.

[9] M. Peters-Golden, C. Canetti, P. Mancuso, and M. J. Coffey, "Leukotrienes: underappreciated mediators of innate immune responses," Journal of Immunology, vol. 174, no. 2, pp. 589-594, 2005.

[10] C. Peres-Buzalaf, L. de Paula, F. G. Frantz et al., "Control of experimental pulmonary tuberculosis depends more on immunostimulatory leukotrienes than on the absence of immunosuppressive prostaglandins," Prostaglandins Leukotrienes and Essential Fatty Acids, vol. 85, no. 2, pp. 75-81, 2011.

[11] A. I. Medeiros, A. Sá-Nunes, E. G. Soares, C. M. Peres, C. L. Silva, and L. H. Faccioli, "Blockade of Endogenous Leukotrienes Exacerbates Pulmonary Histoplasmosis," Infection and Immunity, vol. 72, no. 3, pp. 1637-1644, 2004.

[12] F. F. Anibal, A. P. Rogerio, A. Malheiro et al., "Impact of MK886 on eosinophil counts and phenotypic features in toxocariasis," Scandinavian Journal of Immunology, vol. 65, no. 4, pp. 344-352, 2007.

[13] E. R. Machado, M. T. Ueta, E. V. Lourenço et al., "Leukotrienes play a role in the control of parasite burden in $\mathrm{mu}$ rine strongyloidiasis," Journal of Immunology, vol. 175, no. 6, pp. 3892-3899, 2005.

[14] C. A. Sorgi, A. Secatto, C. Fontanari et al., "Histoplasma capsulatum cell wall $\beta$-glucan induces lipid body formation through CD18, TLR2, and dectin-1 receptors: correlation with leukotriene B 4 generation and role in HIV-1 infection," Journal of Immunology, vol. 182, no. 7, pp. 4025-4035, 2009.

[15] P. L. Fiori, P. Rappelli, and M. F. Addis, "The flagellated parasite Trichomonas vaginalis: new insights into cytopathogenicity mechanisms," Microbes and Infection, vol. 1, no. 2, pp. 149-156, 1999.

[16] R. T. Gazzinelli and E. Y. Denkers, "Protozoan encounters with Toll-like receptor signalling pathways: implications for host parasitism," Nature Reviews Immunology, vol. 6, no. 12, pp. 895-906, 2006.
[17] K. S. Ralston and W. A. Petri Jr, "Tissue destruction and invasion by Entamoeba histolytica," Trends in Parasitology, vol. 27, no. 6, pp. 254-263, 2011.

[18] E. A. García-Zepeda, A. Rojas-López, M. Esquivel-Velázquez, and P. Ostoa-Saloma, "Regulation of the inflammatory immune response by the cytokine/chemokine network in amoebiasis," Parasite Immunology, vol. 29, no. 12, pp. 679-684, 2007.

[19] M. Paintlia, S. Kaur, I. Gupta, N. Ganguly, R. Mahajan, and N. Malla, "Specific IgA response, T-cell subtype and cytokine profile in experimental intravaginal trichomoniasis," Parasitology Research, vol. 88, no. 4, pp. 338-343, 2002.

[20] J. P. Sypek, C. L. Chung, S. E. H. Mayor et al., "Resolution of cutaneous leishmaniasis: interleukin 12 initiates a protective T helper type 1 immune response," Journal of Experimental Medicine, vol. 177, no. 6, pp. 1797-1802, 1993.

[21] N. E. Reiner and C. J. Malemud, "Arachidonic acid metabolism in murine leishmaniasis (Donovani): ex-vivo evidence for increased cyclooxygenase and 5-lipoxygenase activity in spleen cells," Cellular Immunology, vol. 88, no. 2, pp. 501510, 1984.

[22] N. E. Reiner and C. J. Malemud, "Arachidonic acid metabolism by murine peritoneal macrophages infected with Leishmania donovani: in vitro evidence for parasite-induced alterations in cyclooxygenase and lipoxygenase pathways," Journal of Immunology, vol. 134, no. 1, pp. 556-563, 1985.

[23] S. Milano, "Ex vivo evidence for PGE2 and LTB4 involvement in cutaneous leishmaniasis : relation with infection status and cytokine production," Parasitology, vol. 112, no. 1, pp. 13-19, 1996.

[24] C. H. Serezani, J. H. Perrela, M. Russo, M. Peters-Golden, and S. Jancar, "Leukotrienes are essential for the control of Leishmania amazonensis infection and contribute to strain variation in susceptibility," Journal of Immunology, vol. 177, no. 5, pp. 3201-3208, 2006.

[25] P. H. Alvarenga, I. M. B. Francischetti, E. Calvo, A. Sá-Nunes, J. M. C. Ribeiro, and J. F. Andersen, "The function and three-dimensional structure of a thromboxane A2/cysteinyl leukotriene-binding protein from the saliva of a mosquito vector of the malaria parasite," PLoS Biology, vol. 8, no. 11, Article ID e1000547, 2010.

[26] D. E. Champagne, "Antihemostatic molecules from saliva of blood-feeding arthropods," Pathophysiology of Haemostasis and Thrombosis, vol. 34, no. 4-5, pp. 221-227, 2006.

[27] J. M. C. Ribeiro and I. M. B. Francischetti, "Role of arthropod saliva in blood feeding: sialome and post-sialome perspectives," Annual Review of Entomology, vol. 48, pp. 73-88, 2003.

[28] A. Sá-Nunes, A. Bafica, D. A. Lucas et al., "Prostaglandin E2 is a major inhibitor of dendritic cell maturation and function in Ixodes scapularis saliva," Journal of Immunology, vol. 179, no. 3, pp. 1497-1505, 2007.

[29] H. C. Lima and R. G. Titus, "Effects of sand fly vector saliva on development of cutaneous lesions and the immune response to Leishmania braziliensis in BALB/c mice," Infection and Immunity, vol. 64, no. 12, pp. 5442-5445, 1996.

[30] R. G. Titus and J. M. C. Ribeiro, "Salivary gland lysates from the sand fly lutzomyia longipalpis enhance leishmania infectivity," Science, vol. 239, no. 4845, pp. 1306-1308, 1988.

[31] M. C. Monteiro, L. G. Nogueira, A. A. Almeida Souza, J. M. C. Ribeiro, J. S. Silva, and F. Q. Cunha, "Effect of salivary gland extract of Leishmania vector, Lutzomyia longipalpis, on leukocyte migration in OVA-induced immune peritonitis," 
European Journal of Immunology, vol. 35, no. 8, pp. 24242433, 2005.

[32] E. Calvo, B. J. Mans, J. F. Andersen, and J. M. C. Ribeiro, "Function and evolution of a mosquito salivary protein family," Journal of Biological Chemistry, vol. 281, no. 4, pp. 19351942, 2006.

[33] K. S. Babu and S. S. Salvi, "Aspirin and asthma," Chest, vol. 118, no. 5, pp. 1470-1476, 2000.

[34] L. Xiao, P. S. Patterson, C. Yang, and A. A. Lal, "Role of eicosanoids in the pathogenesis of murine cerebral malaria," American Journal of Tropical Medicine and Hygiene, vol. 60, no. 4, pp. 668-673, 1999.

[35] M. English, V. Marsh, E. Amukoye, B. Lowe, S. Murphy, and K. Marsh, "Chronic salicylate poisoning and severe malaria," Lancet, vol. 347, no. 9017, pp. 1736-1737, 1996.

[36] G. E. Grau, H. Heremans, P. F. Piguet et al., "Monoclonal antibody against interferon $\gamma$ can prevent experimental cerebral malaria and its associated overproduction of tumor necrosis factor," Proceedings of the National Academy of Sciences of the United States of America, vol. 86, no. 14, pp. 5572-5574, 1989.

[37] D. M. Yañez, D. D. Manning, A. J. Cooley, W. P. Weidanz, and H. C. Van Der Heyde, "Participation of Lymphocyte Subpopulations in the Pathogenesis of Experimental Murine Cerebral Malaria," Journal of Immunology, vol. 157, no. 4, pp. 1620-1624, 1996.

[38] A. Toda, K. Terawaki, S. Yamazaki, K. Saeki, T. Shimizu, and T. Yokomizo, "Attenuated Th1 induction by dendritic cells from mice deficient in the leukotriene B4 receptor 1," Biochimie, vol. 92, no. 6, pp. 682-691, 2010.

[39] F. Arcoleo, S. Milano, P. D’Agostino, and E. Cillari, "Effect of exogenous leukotriene B4 (LTB4) on BALB/c mice splenocyte production of Th1 and Th2 lymphokines," International Journal of Immunopharmacology, vol. 17, no. 6, pp. 457-463, 1995.

[40] F. Lang, K. S. Lang, P. A. Lang, S. M. Huber, and T. Wieder, "Mechanisms and significance of eryptosis," Antioxidants and Redox Signaling, vol. 8, no. 7-8, pp. 1183-1192, 2006.

[41] F. Lang, E. Gulbins, P. A. Lang, D. Zappulla, and M. Föller, "Ceramide in suicidal death of erythrocytes," Cellular Physiology and Biochemistry, vol. 26, no. 1, pp. 21-28, 2010.

[42] M. Föller, D. Bobbala, S. Koka, S. M. Huber, E. Gulbins, and F. Lang, "Suicide for survival-death of infected erythrocytes as a host mechanism to survive malaria," Cellular Physiology and Biochemistry, vol. 24, no. 3-4, pp. 133-140, 2009.

[43] K. Ayi, F. Turrini, A. Piga, and P. Arese, "Enhanced phagocytosis of ring-parasitized mutant erythrocytes: a common mechanism that may explain protection against falciparum malaria in sickle trait and beta-thalassemia trait," Blood, vol. 104, no. 10, pp. 3364-3371, 2004.

[44] M. Foller, H. Mahmud, S. Gu et al., "Participation of leukotriene C4 in the regulation of suicidal erythrocyte death," Journal of Physiology and Pharmacology, vol. 60, no. 3, pp. 135-143, 2009.

[45] J. F. Thardin, C. M'Rini, M. Beraud et al., "Eicosanoid production by mouse peritoneal macrophages during Toxoplasma gondii penetration: role of parasite and host cell phospholipases," Infection and Immunity, vol. 61, no. 4, pp. 14321441, 1993.

[46] R. M. Locksley, J. Fankhauser, and W. R. Henderson, "Alteration of leukotriene release by macrophages ingesting Toxoplasma gondii," Proceedings of the National Academy of Sciences of the United States of America, vol. 82, no. 20, pp. 6922-6926, 1985.
[47] E. C. Yong, E. Y. Chi, and W. R. Henderson Jr, "Toxoplasma gondii alters eicosanoid release by human mononuclear phagocytes: role of leukotrienes in interferon $\gamma$-induced antitoxoplasma activity," Journal of Experimental Medicine, vol. 180, no. 5, pp. 1637-1648, 1994.

[48] W. R. Henderson Jr and E. Y. Chi, "The importance of leukotrienes in mast cell-mediated Toxoplasma gondii cytotoxicity," Journal of Infectious Diseases, vol. 177, no. 5, pp. 1437-1443, 1998.

[49] J. Aliberti, C. Serhan, and A. Sher, "Parasite-induced lipoxin A4 is an endogenous regulator of IL-12 production and immunopathology in Toxoplasma gondii infection," Journal of Experimental Medicine, vol. 196, no. 9, pp. 1253-1262, 2002.

[50] M. J. Coffey, S. M. Phare, S. Cinti, M. Peters-Golden, and P. H. Kazanjian, "Granulocyte-macrophage colony-stimulating factor upregulates reduced 5-lipoxygenase metabolism in peripheral blood monocytes and neutrophils in acquired immunodeficiency syndrome," Blood, vol. 94, no. 11, pp. 38973905, 1999.

[51] M. Munoz, O. Liesenfeld, and M. M. Heimesaat, "Immunology of Toxoplasma gondii," Immunological Reviews, vol. 240, no. 1, pp. 269-285, 2011.

[52] S. B. Porter and M. A. Sande, "Toxoplasmosis of the central nervous system in the acquired immunodeficiency syndrome," New England Journal of Medicine, vol. 327, no. 23, pp. 1643-1648, 1992.

[53] E. Mayatepek, B. Flock, R. Zelezny, K. Kreutzer, and H. J. Von Giesen, "LTB4 and LTC4 are absent in the cerebrospinal fluid of human immunodeficiency virus type 1-seropositive persons with toxoplasmic encephalitis: evidence for inhibition of 5-lipoxygenase by Toxoplasma gondii," Journal of Infectious Diseases, vol. 179, no. 3, pp. 714-716, 1999.

[54] E. Cunha-Neto, P. C. Teixeira, S. G. Fonseca, A. M. Bilate, and J. Kalil, "Myocardial gene and protein expression profiles after autoimmune injury in Chagas' disease cardiomyopathy," Autoimmunity Reviews, 2010.

[55] C. D. Funk, "Leukotriene modifiers as potential therapeutics for cardiovascular disease," Nature Reviews Drug Discovery, vol. 4, no. 8, pp. 664-672, 2005.

[56] B. Sokołowska, J. Dropinski, M. Rzeszutko, W. Szczeklik, M. Sanak, and A. Szczeklik, "Influence of leukotriene biosynthesis inhibition on heart rate in patients with atrial fibrillation," International Journal of Cardiology, vol. 145, no. 3, pp. 625626, 2010.

[57] M. M. E. de Bracco, L. Sterin Borda, and S. Fink, "Stimulatory effect of lymphocytes from Chagas' patients on spontaneously beating rat atria," Clinical and Experimental Immunology, vol. 55, no. 2, pp. 405-412, 1984.

[58] G. Gorelik, E. Borda, M. Postan, S. Gonzalez Cappa, and L. Sterin-Borda, "T lymphocytes from T. cruzi-infected mice alter heart contractility: participation of arachidonic acid metabolites," Journal of Molecular and Cellular Cardiology, vol. 24, no. 1, pp. 9-20, 1992.

[59] A. D. Luster and A. M. Tager, "T-cell trafficking in asthma: lipid mediators grease the way," Nature Reviews Immunology, vol. 4, no. 9, pp. 711-724, 2004.

[60] J. J. Wirth and F. Kierszenbaum, "Stimulatory effects of leukotriene B4 on macrophage association with and intracellular destruction of Trypanosoma cruzi," Journal of Immunology, vol. 134, no. 3, pp. 1989-1993, 1985.

[61] J. J. Wirth and F. Kierszenbaum, "Effects of leukotriene C4 on macrophage association with and intracellular fate of Trypanosoma cruzi," Molecular and Biochemical Parasitology, vol. 15 , no. 1, pp. 1-10, 1985. 
[62] A. Talvani, F. S. Machado, G. C. Santana et al., "Leukotriene B4 induces nitric oxide synthesis in Trypanosoma cruziinfected murine macrophages and mediates resistance to infection," Infection and Immunity, vol. 70, no. 8, pp. 42474253, 2002.

[63] C. L. Borges, R. Cecchini, V. L. H. Tatakihara et al., "5Lipoxygenase plays a role in the control of parasite burden and contributes to oxidative damage of erythrocytes in murine Chagas' disease," Immunology Letters, vol. 123, no. 1, pp. 38-45, 2009.

[64] W. R. Pavanelli, F. R. S. Gutierrez, F. S. Mariano et al., "5-Lipoxygenase is a key determinant of acute myocardial inflammation and mortality during Trypanosoma cruzi infection," Microbes and Infection, vol. 12, no. 8-9, pp. 587-597, 2010.

[65] C. Panis, T. L. Mazzuco, C. Z. F. Costa et al., "Trypanosoma cruzi: effect of the absence of 5-lipoxygenase (5-LO)-derived leukotrienes on levels of cytokines, nitric oxide and iNOS expression in cardiac tissue in the acute phase of infection in mice," Experimental Parasitology, vol. 127, no. 1, pp. 58-65, 2011.

[66] M. F. Shaio and P. R. Lin, "Influence of humoral immunity on leukotriene B4 production by neutrophils in response to Trichomonas vaginalis stimulation," Parasite Immunology, vol. 17, no. 3, pp. 127-133, 1995.

[67] M. F. Shaio and P. R. Lin, "Leucotriene B4 levels in the vaginal discharges from cases of trichomoniasis," Annals of Tropical Medicine and Parasitology, vol. 89, no. 1, pp. 85-88, 1995.

[68] W. Wang and K. Chadee, "Entamoeba histolytica alters arachidonic acid metabolism in macrophages in vitro and in vivo," Immunology, vol. 76, no. 2, pp. 242-250, 1992.

[69] D. E. Elliott, R. W. Summers, and J. V. Weinstock, "Helminths as governors of immune-mediated inflammation," International Journal for Parasitology, vol. 37, no. 5, pp. 457-464, 2007.

[70] P. J. Hotez, P. J. Brindley, J. M. Bethony, C. H. King, E. J. Pearce, and J. Jacobson, "Helminth infections: the great neglected tropical diseases," Journal of Clinical Investigation, vol. 118, no. 4, pp. 1311-1321, 2008.

[71] L. H. Faccioli, A. I. Medeiros, A. Malheiro, R. C. L. R. Pietro, A. Januario, and B. B. Vargaftig, "Interleukin-5 modulates interleukin-8 secretion in eosinophilic inflammation," Mediators of Inflammation, vol. 7, no. 1, pp. 41-47, 1998.

[72] L. H. Faccioli, V. F. Mokwa, C. L. Silva et al., "IL-5 drives eosinophils from bone marrow to blood and tissues in a guinea-pig model of visceral larva migrans syndrome," Mediators of Inflammation, vol. 5, no. 1, pp. 24-31, 1996.

[73] W. P. Zheng and R. A. Flavell, "The transcription factor GATA-3 is necessary and sufficient for Th2 cytokine gene expression in CD4 T cells," Cell, vol. 89, no. 4, pp. 587-596, 1997.

[74] T. Nakayama and M. Yamashita, "Initiation and maintenance of Th2 cell identity," Current Opinion in Immunology, vol. 20, no. 3, pp. 265-271, 2008.

[75] M. E. Rothenberg, "Eosinophilia," New England Journal of Medicine, vol. 338, no. 22, p. 1592, 1998.

[76] G. J. Gleich and D. A. Loegering, "Immunobiology of eosinophils," Annual Review of Immunology, vol. 2, pp. 429-459, 1984.

[77] R. Moqbel and P. Lacy, "Exocytotic events in eosinophils and mast cells: editorial," Clinical and Experimental Allergy, vol. 29, no. 8, pp. 1017-1022, 1999.

[78] M. E. Rothenberg and S. P. Hogan, “The eosinophil," Annual Review of Immunology, vol. 24, pp. 147-174, 2006.
[79] Q. Hamid and M. Tulic, "Immunobiology of asthma," Annual Review of Physiology, vol. 71, pp. 489-507, 2009.

[80] C. Blanchard and M. E. Rothenberg, "Chapter 3 Biology of the Eosinophil," Advances in Immunology C, vol. 101, pp. 81$121,2009$.

[81] P. Lacy and R. Moqbel, "Eosinophil cytokines," Chemical Immunology, vol. 76, pp. 134-155, 2000.

[82] H. J. Gould and B. J. Sutton, "IgE in allergy and asthma today," Nature Reviews Immunology, vol. 8, no. 3, pp. 205-217, 2008.

[83] K. Furuichi, J. Rivera, and C. Isersky, “The receptor for immunoglobulin E on rat basophilic leukemia cells: effect of ligand binding on receptor expression," Proceedings of the $\mathrm{Na}$ tional Academy of Sciences of the United States of America, vol. 82, no. 5, pp. 1522-1525, 1985.

[84] P. A. Knight, J. K. Brown, and A. D. Pemberton, "Innate immune response mechanisms in the intestinal epithelium: potential roles for mast cells and goblet cells in the expulsion of adult Trichinella spiralis," Parasitology, vol. 135, no. 6, pp. 655-670, 2008.

[85] R. Moqbel, D. Wakelin, and A. J. MacDonald, "Release of leukotrienes during rapid expulsion of Trichinella spiralis from immune rats," Immunology, vol. 60, no. 3, pp. 425-430, 1987.

[86] M. H. Perdue, J. K. Ramage, D. Burget, J. Marshall, and S. Masson, "Intestinal mucosal injury is associated with mast cell activation and leukotriene generation during Nippostrongylus-induced inflammation in the rat," Digestive Diseases and Sciences, vol. 34, no. 5, pp. 724-731, 1989.

[87] M. W. Kennedy and F. Qureshi, "Stage-specific secreted antigens of the parasitic larval stages of the nematode Ascaris," Immunology, vol. 58, no. 3, pp. 517-522, 1986.

[88] M. W. Kennedy, F. Qureshi, M. Haswell-Elkins, and D. B. Elkins, "Homology and heterology between the secreted antigens of the parasitic larval stages of Ascaris lumbricoides and Ascaris suum," Clinical and Experimental Immunology, vol. 67, no. 1, pp. 20-30, 1987.

[89] Y. Xia, H. J. Spence, J. Moore et al., "The ABA-1 allergen of Ascaris lumbricoides: sequence polymorphism, stage and tissue-specific expression, lipid binding function, and protein biophysical properties," Parasitology, vol. 120, no. 2, pp. 211224, 2000.

[90] K. M. Pfarr, A. Y. Debrah, S. Specht, and A. Hoerauf, "Filariasis and lymphoedema," Parasite Immunology, vol. 31, no. 11, pp. 664-672, 2009.

[91] H. L. Smith and T. V. Rajan, "Inhibitors of the lipoxygenase pathway block development of Brugia malayi L3 in vitro," Journal of Parasitology, vol. 87, no. 2, pp. 242-249, 2001.

[92] E. Lobos, R. Zahn, N. Weiss, and T. B. Nutman, "A major allergen of lymphatic filarial nematodes is a parasite homolog of the $\gamma$-glutamyl transpeptidase," Molecular Medicine, vol. 2, no. 6 , pp. 712-724, 1996.

[93] P. F. Weller, D. L. Longworth, and J. J. Jaffe, "Leukotriene C4 synthesis catalyzed by Dirofilaria immitis glutathione S-transferase," American Journal of Tropical Medicine and Hygiene, vol. 40, no. 2, pp. 171-175, 1989.

[94] L. A. Marcos, A. Terashima, H. L. DuPont, and E. Gotuzzo, "Strongyloides hyperinfection syndrome: an emerging global infectious disease," Transactions of the Royal Society of Tropical Medicine and Hygiene, vol. 102, no. 4, pp. 314-318, 2008.

[95] A. P. Rogerio, A. Sá-Nunes, D. A. Albuquerque et al., "Lafoensia pacari extract inhibits IL-5 production in toxocariasis," Parasite Immunology, vol. 25, no. 7, pp. 393-400, 2003. 
[96] C. J. Sanderson, D. J. Warren, and M. Strath, "Identification of a lymphokine that stimulates eosinophil differentiation in vitro. Its relationship to interleukin 3, and functional properties of eosinophils produced in cultures," Journal of Experimental Medicine, vol. 162, no. 1, pp. 60-74, 1985.

[97] Y. Yamaguchi, T. Suda, J. Suda et al., "Purified interleukin 5 supports the terminal differentiation and proliferation of murine eosinophilic precursors," Journal of Experimental Medicine, vol. 167, no. 1, pp. 43-56, 1988.

[98] E. J. Clutterback and C. J. Sanderson, "Human eosinophil hematopoiesis studied in vitro by means of murine eosinophil differentiation factor (IL5): production of functionally active eosinophils from normal human bone marrow," Blood, vol. 71, no. 3, pp. 646-651, 1988.

[99] E. Coeffier, D. Joseph, and B. B. Vargaftig, "Activation of guinea pig eosinophils by human recombinant IL-5: selective priming to platelet-activating factor-acether and interference of its antagonists," Journal of Immunology, vol. 147, no. 8, pp. 2595-2602, 1991.

[100] K. A. Yamaoka and J. P. Kolb, "Leukotriene B4 induces interleukin 5 generation from human T lymphocytes," European Journal of Immunology, vol. 23, no. 10, pp. 2392-2398, 1993.

[101] P. C. Beaver, C. H. Snyder, G. M. Carrera, J. H. Dent, and J. W. Lafferty, "Chronic eosinophilia due to visceral larva migrans; report of three cases," Pediatrics, vol. 9, no. 1, pp. 7-19, 1952.

[102] V. C. C. Dattoli, S. M. Freire, L. R. Mendonça, P. C. Santos, R. Meyer, and N. M. Alcantara-Neves, "Toxocara canis infection is associated with eosinophilia and total IgE in blood donors from a large Brazilian centre," Tropical Medicine and International Health, vol. 16, no. 4, pp. 514-517, 2011.

[103] A. P. Rogerio, A. Sá-Nunes, D. A. Albuquerque, E. G. Soares, and L. H. Faccioli, "Anti-eosinophilic effect of Lafoensia pacari in toxocariasis," Phytomedicine, vol. 15, no. 5, pp. 348$357,2008$.

[104] J. Buijs, W. H. Lokhorst, J. Robinson, and F. P. Nijkamp, "Toxocara canis-induced murine pulmonary inflammation: analysis of cells and proteins in lung tissue and bronchoalveolar lavage fluid," Parasite Immunology, vol. 16, no. 1, pp. 1-9, 1994.

[105] S. R. Barthel, M. W. Johansson, D. M. McNamee, and D. F. Mosher, "Roles of integrin activation in eosinophil function and the eosinophilic inflammation of asthma," Journal of Leukocyte Biology, vol. 83, no. 1, pp. 1-12, 2008.

[106] A. Dobrina, R. Menegazzi, T. M. Carlos et al., "Mechanisms of eosinophil adherence to cultured vascular endothelial cells: eosinophils bind to the cytokine-induced endothelial ligand vascular cell adhesion molecule-1 via the very late activation antigen-4 integrin receptor," Journal of Clinical Investigation, vol. 88 , no. 1 , pp. 20-26, 1991.

[107] G. Q. Jia, J. A. Gonzalo, A. Hidalgo, D. Wagner, M. Cybulsky, and J. C. Gutierrez-Ramos, "Selective eosinophil transendothelial migration triggered by eotaxin via modulation of Mac-1/ICAM-1 and VLA-4/VCAM-1 interactions," International Immunology, vol. 11, no. 1, pp. 1-10, 1999.

[108] M. Nagata, K. Saito, K. Tsuchiya, and Y. Sakamoto, "Leukotriene D4 upregulates eosinophil adhesion via the cysteinyl leukotriene 1 receptor," Journal of Allergy and Clinical Immunology, vol. 109, no. 4, pp. 676-680, 2002.

[109] D. Carlos, E. R. Machado, L. de Paula et al., "Evidence for eosinophil recruitment, leukotriene B 4 production and mast cell hyperplasia following Toxocara canis infection in rats," Brazilian Journal of Medical and Biological Research, vol. 44, no. 4, pp. 319-326, 2011.
[110] T. A. Wynn, R. W. Thompson, A. W. Cheever, and M. M. Mentink-Kane, "Immunopathogenesis of schistosomiasis," Immunological Reviews, vol. 201, pp. 156-167, 2004.

[111] R. Moqbel, S. P. Sass Kuhn, E. J. Goetzl, and A. B. Kay, "Enhancement of neutrophil- and eosinophil-mediated complement-dependent killing of schistosomula of Schistosoma mansoni in vitro by leukotriene B4," Clinical and Experimental Immunology, vol. 52, no. 3, pp. 519-527, 1983.

[112] S. Nutten, F. Trottein, A. S. Gounni, J. P. Papin, A. Capron, and M. Capron, "From allergy to schistosomes: role of Fc receptors and adhesion molecules in eosinophil effector function," Memorias do Instituto Oswaldo Cruz, vol. 92, pp. 9-14, 1997.

[113] R. Moqbel, A. J. Macdonald, O. Cromwell, and A. B. Kay, "Release of leukotriene C4 (LTC4) from human eosinophils following adherence to IgE- and IgG-coated schistosomula of Schistosoma mansoni," Immunology, vol. 69, no. 3, pp. 435442, 1990.

[114] B. Salafsky and A. C. Fusco, "Schistosoma mansoni: a comparison of secreted vs nonsecreted eicosanoids in developing schistosomulae and adults," Experimental Parasitology, vol. 64, no. 3, pp. 361-367, 1987.

[115] Y. X. He, B. Salafsky, and K. Ramaswamy, "Comparison of skin invasion among three major species of Schistosoma," Trends in Parasitology, vol. 21, no. 5, pp. 201-203, 2005.

[116] A. C. Fusco, B. Salafsky, and K. Delbrook, "Schistosoma mansoni: production of cercarial eicosanoids as correlates of penetration and transformation," Journal of Parasitology, vol. 72, no. 3, pp. 397-404, 1986.

[117] A. C. Fusco, B. Salafsky, K. Whitely, and S. Yohe, "Schistosoma mansoni: $\mathrm{pH}$ dependence of cercarial eicosanoid production, penetration, and transformation," Experimental Parasitology, vol. 64, no. 2, pp. 139-146, 1987.

[118] A. M. Brunati, M. A. Pagano, A. Bindoli, and M. P. Rigobello, "Thiol redox systems and protein kinases in hepatic stellate cell regulatory processes," Free Radical Research, vol. 44, no. 4, pp. 363-378, 2010.

[119] L. A. Paiva, C. M. Maya-Monteiro, C. Bandeira-Melo et al., "Interplay of cysteinyl leukotrienes and TGF- $\beta$ in the activation of hepatic stellate cells from Schistosoma mansoni granulomas," Biochimica et Biophysica Acta, vol. 1801, no. 12, pp. 1341-1348, 2010.

[120] D. W. Perng, Y. C. Wu, K. T. Chang et al., "Leukotriene C4 induces TGF- $\beta 1$ production in airway epithelium via p38 kinase pathway," American Journal of Respiratory Cell and Molecular Biology, vol. 34, no. 1, pp. 101-107, 2006.

[121] N. Sato, Y. Ito, T. Iida, K. Fukuyama, and W. L. Epstein, "Characterization of two dipeptidases purified from hepatic schistosome egg granulomas in mice. Leukotriene D4 hydrolases of granulomatous tissue," Biochemical Journal, vol. 284, no. 3, pp. 885-890, 1992.

[122] P. Montuschi, A. Sala, S. E. Dahlén, and G. Folco, "Pharmacological modulation of the leukotriene pathway in allergic airway disease," Drug Discovery Today, vol. 12, no. 9-10, pp. 404-412, 2007.

[123] S. S. Salvi, M. T. Krishna, A. P. Sampson, and S. T. Holgate, "The anti-inflammatory effects of leukotriene-modifying drugs and their use in asthma," Chest, vol. 119, no. 5, pp. 1533-1546, 2001.

[124] R. J. Flynn, G. Mulcahy, and H. M. Elsheikha, "Coordinating innate and adaptive immunity in Fasciola hepatica infection: implications for control," Veterinary Parasitology, vol. 169, no. 3-4, pp. 235-240, 2010. 
[125] S. F. Ali, A. Joachim, and A. Daugschies, "Eicosanoid production by adult Fasciola hepatica and plasma eicosanoid patterns during fasciolosis in sheep," International Journal for Parasitology, vol. 29, no. 5, pp. 743-748, 1999.

[126] R. Zafra, L. Buffoni, A. Martínez-Moreno, A. Pérez-Écija, F. J. Martinez-Moreno, and J. Pérez, "A study of the liver of goats immunized with a synthetic peptide of the Sm14 antigen and challenged with Fasciola hepatica," Journal of Comparative Pathology, vol. 139, no. 4, pp. 169-176, 2008. 


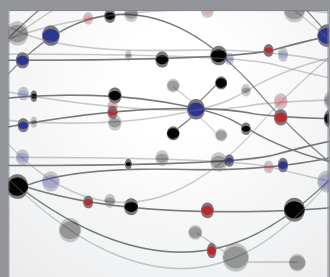

The Scientific World Journal
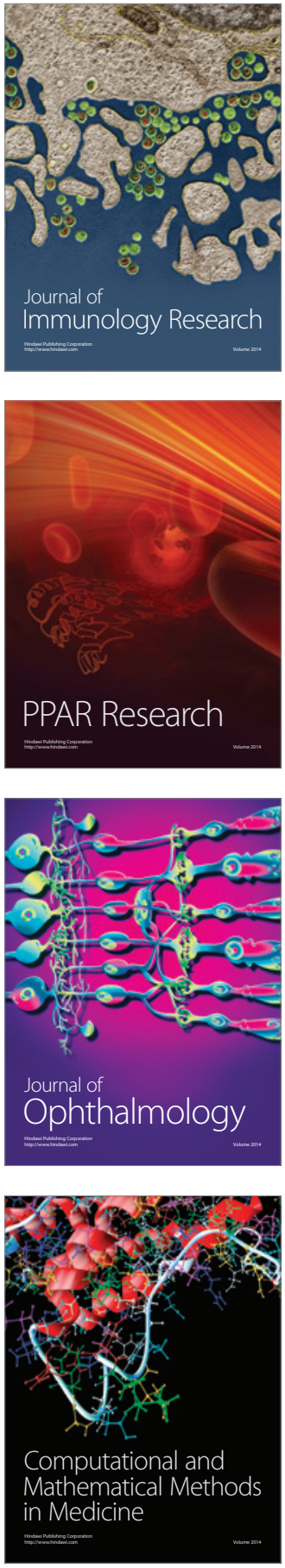

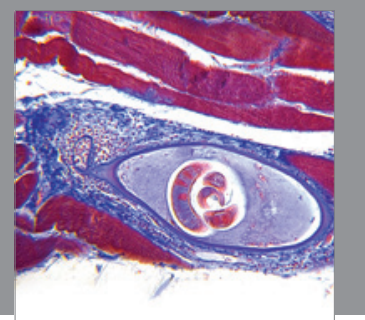

Gastroenterology

Research and Practice
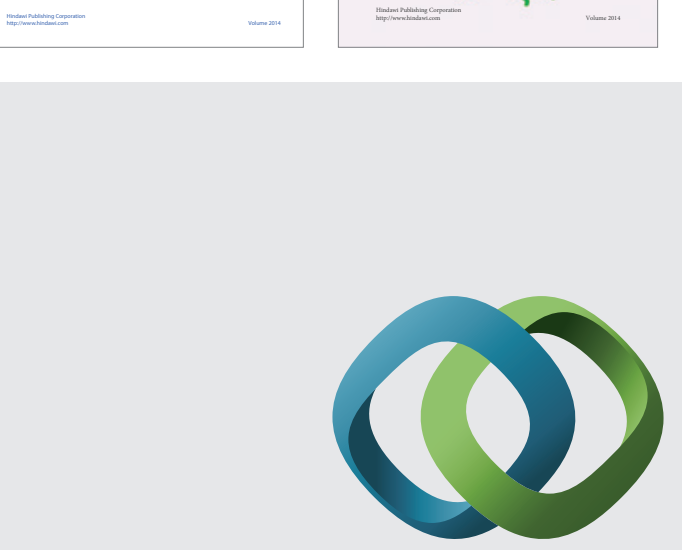

\section{Hindawi}

Submit your manuscripts at

http://www.hindawi.com
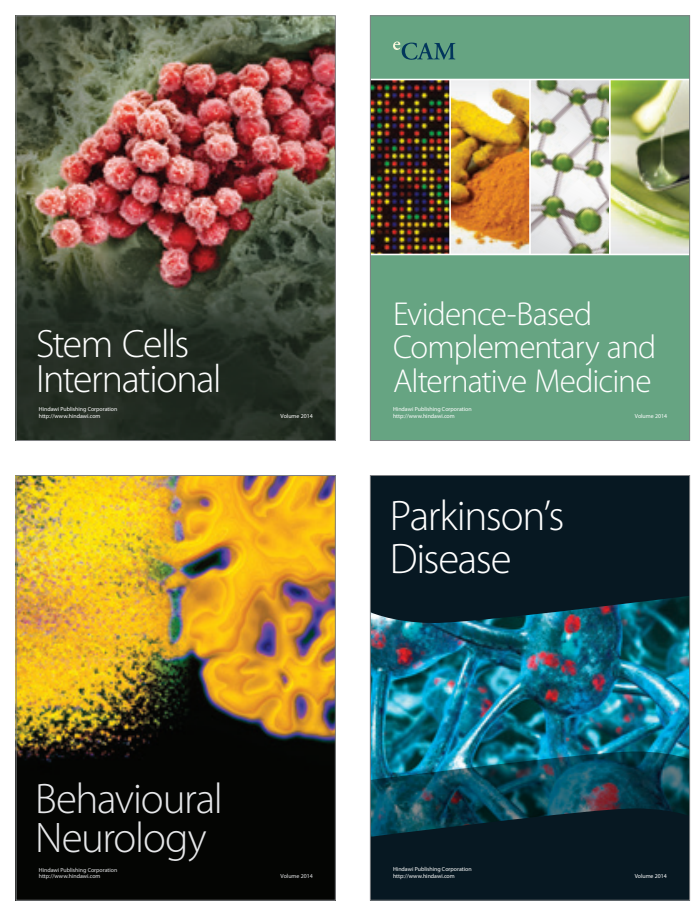

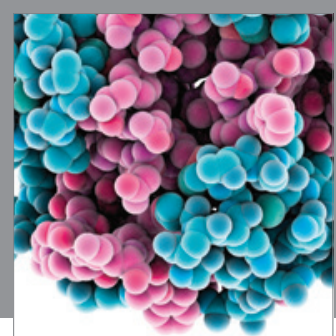

Journal of
Diabetes Research

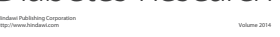

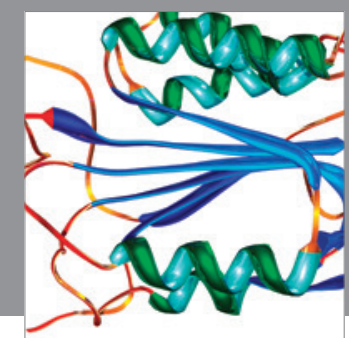

Disease Markers
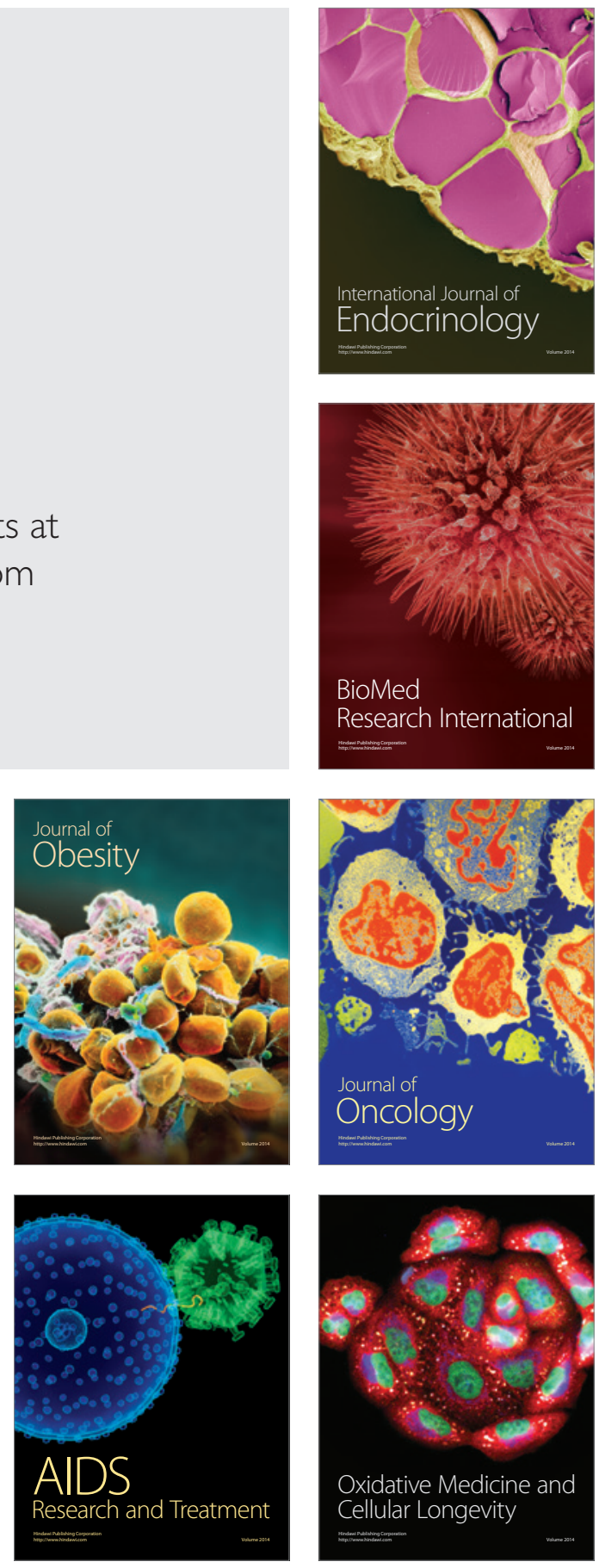